\title{
Glaucomatous Optic Neuropathy: The Dark Side of the Moon
}

\author{
Shahin Yazdani ${ }^{1,2}$, MD \\ ${ }^{1}$ Ocular Tissue Engineering Research Center, Shahid Beheshti University of Medical Sciences, Tehran, Iran \\ ${ }^{2}$ Ophthalmic Research Center, Research Institute for Ophthalmology and Vision Research, Shahid Beheshti University of \\ Medical Sciences, Tehran, Iran \\ ORCID: \\ Shahin Yazdani: http://orcid.org/0000-0002-9583-1434
}

J Ophthalmic Vis Res 2021; 16 (2): 148-150

Glaucoma is an enigmatic eye condition and serves as a perfect example for an ocular disease with complex pathophysiology, multifactorial nature, and close interplay with systemic factors. Glaucomatous optic neuropathy (GON) is also probably the most important and prevalent eye condition linked to events within the central nervous system (CNS). None of these is an overstatement when one recalls that the optic nerve head, the site where GON is diagnosed and monitored, is only one small sector of the second cranial nerve, otherwise known as the optic nerve. The major portion of the optic nerve courses in the CNS and acquires physiologic features of neurons residing in the CNS, for example myelination of fibers, just posterior to the lamina cribrosa (LC). Another important fact is that the optic nerve is composed of bundled axons of retinal ganglion cells (RGCs) which have the privilege of "dual citizenship" resting partly in a peripheral organ and partly within the CNS, the boundary being at the LC.

The past decades have witnessed a surge of interest and a wealth of information on previously unknown and less explored aspects of glaucoma. These include the role of systemic factors such as vascular dysregulation, nocturnal systemic hypotension, positional intraocular pressure (IOP) elevation, and episodes of hypoxia due to sleep apnea. ${ }^{[1-5]}$ It has also become more evident that the damage associated with GON is not limited to the optic nerve and secondary/concomitant damage is present at higher centers within the CNS including the lateral geniculate body and primary visual cortex. ${ }^{[6,7]}$ These observations are in favor of the notion that GON represents a neurodegenerative process beyond the eye.

It has become increasingly known that compartments (and pressures within) adjacent to the optic nerve other than the intraocular compartment and IOP have an important role in maintaining its homeostasis. ${ }^{[8]}$ The retrolaminar portion of the optic nerve has attracted much attention and the most important compartment in this region seems to be the subarachnoid space bathed in cerebrospinal fluid (CSF) which is connected to the subarachnoid space of the brain. ${ }^{[9,10]}$

One particular region of interest is the LC, where IOP and CSF pressure (CSFP) meet, exerting pressure on either side of the lamina, thus creating a pressure gradient. The LC has long been considered as a major site of insult to RGCs triggering cell loss and apoptosis. Various in vivo observations using enhanced depth imaging optical coherence tomography (EDI-OCT) and histological studies in animal and human eyes have demonstrated LC changes including displacement, compaction and bowing associated with GON. ${ }^{[11,12]}$ One simplified scheme used to conceptualize glaucomatous damage is to focus on mechanical factors at this region and ignore other physiologic alterations such as impaired nutrition and reduced clearance of neurotoxins. With this simplified mechanical scheme, one can consider IOP and CSFP as two opposing forces which not only affect LC position but also exert stress and strain on this important structure and the delicate retinal nerve fibers protected within the laminar pores. If the normal physiologic balance between these two pressure components is disturbed, the lamina becomes 
compressed and displaced either posteriorly, as in the case of GON, or anteriorly as in intracranial hypertension.

Having emphasized the importance of the pressure balance at the region of the LC, one cannot neglect the importance of intrinsic LC characteristics such as laminar area, thickness, rigidity/elasticity, compliance, deformability, and pore size. It has been shown that LC thickness may vary in different forms of glaucoma ${ }^{[13-15]}$ and might arguably be associated with central corneal thickness, which may serve as a more accessible surrogate biomarker. ${ }^{[16]}$

In this issue of JOVR, Cruz et $\mathrm{al}^{[17]}$ report trans-LC pressure gradient (TLCPG) in addition to ocular perfusion pressure (OPP) in a cohort of subjects with definite or suspicious open angle glaucoma stratified by optic disc size. Although this group of investigators found no significant difference in OPP, they reported significantly larger TLCPG in eyes with larger discs. This may reflect higher susceptibility of larger optic nerves to glaucomatous damage. This observation follows basic physical rules such as Laplace's law, ${ }^{[18]}$ which explains that strain in a pressurized hollow structure is directly correlated with its diameter and inversely correlated with its thickness. ${ }^{[19]}$ Although there are limitations to applying purely physical rules to live tissue, the calculated TLCPG reported by the authors seems to be a fairly reasonable reflection of the actual physiologic reality.

The authors are to be commended for their study, but at the same time we need to consider certain limitations of their methodology, partly addressed by the authors. First, CSFP was not actually measured but rather derived mathematically using proxy parameters such as BMI, diastolic blood pressure, and age. However, one may argue that even with lumbar puncture and obtaining CSFP values, the readings may not accurately reflect actual CSFPs at the LC. Second, it is not clear whether major determinants of TLCPG, that is, IOP and CSFP, were comparable among the study groups and that it would be safe to conclude that the observed difference in TLCPG among the study groups was only due to different optic nerve size. Last, it would have been interesting if LC thickness had also been evaluated by EDI-OCT and its measurements had been taken into account.
The study by Cruz et $\mathrm{al}^{[17]}$ helps add to the literature much needed data which the ophthalmology community and glaucoma specialists in particular have been missing: the myriad of complex and less recognized factors intertwined in the pathophysiology of GON lurking in less accessible regions of the optic nerve, or "the dark side of the moon."

\section{REFERENCES}

1. Flammer J, Orgül S, Costa VP, Orzalesi N, Krieglstein GK, Serra LM, Renard JP, Stefánsson E. The impact of ocular blood flow in glaucoma. Prog Retin Eye Res 2002;21:359393.

2. Buchanan RA, Williams TD. Intraocular pressure, ocular pulse pressure and body position. Am J Optom Physiol Opt 1985;62:59-62.

3. Linder BJ, Trick GL, Wolf ML. Altering body position affects intraocular pressure and visual function. Invest Ophthalmol Vis Sci 1988;29:1492-1497.

4. Mojon DS, Hess CW, Goldblum D, Fleischhauer J, Koerner F, Bassetti C, et al. High prevalence of glaucoma in patients with sleep apnea syndrome. Ophthalmology 1999;106:1009-1012.

5. Marcus DM, Costarides AP, Gokhale P, Papastergiou G, Miller JJ, Johnson MH, Chaudhary BA. Sleep disorders: a risk factor for normal-tension glaucoma? J Glaucoma 2001;10:177-183.

6. Gupta N, Yücel YH. Brain changes in glaucoma. Eur J Ophthalmol 2003;13:S32-S35.

7. Gupta N, Ang LC, Noël de Tilly L, Bidaisee L, Yücel YH. Human glaucoma and neural degeneration in intracranial optic nerve, lateral geniculate nucleus, and visual cortex. Br J Ophthalmol 2006;90:674-678.

8. Killer HE. Compartment syndromes of the optic nerve and open-angle glaucoma. J Glaucoma 2013;22:S19-S20.

9. Jonas JB. Role of cerebrospinal fluid pressure in the pathogenesis of glaucoma. Acta Ophthalmol 2011;89:505-514.

10. Killer HE, Jaggi GP, Flammer J, Miller NR. Is openangle glaucoma caused by impaired cerebrospinal fluid circulation around the optic nerve? Clin Exp Ophthalmol 2008;36:308-311.

11. Jonas JB, Königsreuther KA, Naumann GOH. Optic disc histomorphometry in normal eyes and eyes with secondary angle-closure glaucoma. II. Parapapillary region. Graefe's Arch Clin Exp Ophthalmol 1992;230:134139.

12. Downs JC, Girkin CA. Lamina cribrosa in glaucoma. Curr Opin Ophthalmol 2017;28:113-119.

13. Park HY, Jeon SH, Park CK. Enhanced depth imaging detects lamina cribrosa thickness differences in normal tension glaucoma and primary open-angle glaucoma. Ophthalmology 2012;119:10-20. 
14. Kim M, Bojikian KD, Slabaugh MA, Ding L, Chen PP. Lamina depth and thickness correlate with glaucoma severity. Indian J Ophthalmol 2016;64:358-363.

15. Kim YW, Jeoung JW, Kim YK, Park KH. Clinical implications of in vivo lamina cribrosa imaging in glaucoma. $J$ Glaucoma 2017;26:753-761.

16. Jonas JB, Holbach L. Central corneal thickness and thickness of the lamina cribrosa in human eyes. Invest Ophthalmol Vis Sci 2005;46:1275-1279.

\section{Correspondence to:}

Shahin Yazdani, MD. Ophthalmic Research Center, Research Institute for Ophthalmology and Vision Science, Shahid Beheshti University of Medical Sciences, 23 Paidar Fard, Bostan 9, Pasdaran Ave., Tehran 16666, Iran.

Email: shahinyazdani@yahoo.com

Received: 05-01-2021 Accepted: 13-02-2021

\begin{tabular}{|l|}
\hline \multicolumn{1}{|c|}{ Access this article online } \\
\hline Website: https://knepublishing.com/index.php/JOVR \\
\hline DOI: 10.18502/jovr.v16i2.9076 \\
\hline
\end{tabular}

17. Cruz NFS, Santos KS, Matuoka ML, Kasahara N. Translaminar pressure difference and ocular perfusion pressure in glaucoma patients with different optic disc sizes. J Ophthalmic Vis Res 2021;16:171-177.

18. Szczudlowski K. Glaucoma hypothesis: application of the law of Laplace. Med Hypotheses 1979;5:481-486.

19. Baneke AJ, Aubry J, Viswanathan AC, Plant GT. The role of intracranial pressure in glaucoma and therapeutic implications. Eye 2020;34:178-191.

This is an open access journal, and articles are distributed under the terms of the Creative Commons Attribution-NonCommercial-ShareAlike 4.0 License, which allows others to remix, tweak, and build upon the work non-commercially, as long as appropriate credit is given and the new creations are licensed under the identical terms.

How to cite this article: Yazdani S. Glaucomatous Optic Neuropathy: The Dark Side of the Moon. J Ophthalmic Vis Res 2021;16:148-150. 